\title{
Investigating the Double-Move in Pedagogy in a Grade 4 Namibian Science Classroom: A Cultural Historical Analysis
}

\author{
Joanne Hardman'1, Beatha Set ${ }^{2}$ \\ ${ }^{1}$ University of Cape Town, Cape Town, South Africa \\ ${ }^{2}$ University of Namibia, Windhoek, Namibia \\ Email: joanne.hardman@uct.ac.za,bset@unam.na
}

How to cite this paper: Hardman, J., \& Set, B. (2021). Investigating the Double-Move in Pedagogy in a Grade 4 Namibian Science Classroom: A Cultural Historical Analysis. Creative Education, 12, 453-469. https://doi.org/10.4236/ce.2021.122032

Received: December 7, 2020

Accepted: February 23, 2021

Published: February 26, 2021

Copyright $\odot 2021$ by author(s) and Scientific Research Publishing Inc. This work is licensed under the Creative Commons Attribution International License (CC BY 4.0).

http://creativecommons.org/licenses/by/4.0/ (c) (i) Open Access

\begin{abstract}
This paper investigates how a teacher in a rural school in Namibia teaches science. Of interest to us is the nature of the classroom discourse in constructing scientific knowledge that is meaningful to students. We draw on the work of Vygotsky (1978) in order to understand teaching/learning as dialectically entailed and to understand the notion of scientific and spontaneous concepts as distinct from science concepts, and operationalise his pedagogical theory utilising Hedegaard's (1998) notion of the double-move in pedagogy as fundamental to meaningful engagement. Through a detailed analysis of one teacher's pedagogical discourse we show how the linking of scientific and spontaneous concepts can either facilitate or hinder learning. Our analysis points to the importance of co-constructing meaning in the class, between teacher and taught and illustrates how analogies and metaphors can fail to create meaning in a classroom if the teacher does not recruit the learners' own everyday concepts.
\end{abstract}

\section{Keywords}

Science Classroom, Pedagogical Discourse, Culture

\section{Introduction}

\subsection{The Background of the Namibian Curriculum}

To redress the inequality in the Namibian education system that was part of the apartheid, the Namibian education system went through comprehensive reforms that encompass Language in Education Policy (LiEP), curriculum revision, as well as the assessment methods. The Namibian education reforms were under- 
pinned by major goals such as accessibility, equity, democracy, and quality (Ministry of Education and Culture, 1993). When Namibia got its independence in 1990, the new Ministry of Education and Culture proposed a mode of pedagogical transformation through the introduction of the new curriculum known as Learner-Centred approach (LCE) (Ministry of Basic Education, Sport and Culture) (Ministry of Education and Culture, 2008). The main ideology that underpinned the LCE curriculum is that "the starting point at each stage of a learning process is each learner's existing knowledge, skills, interests and understanding, derived from previous experience in and out of school" (Ministry of Education and Culture, 2003: p. 25). This curriculum aimed to replace the Bantu education with a teacher-centred approach and to move away from the subject-centred curriculum that was inherited from the colonial legacy (Tabachnick, 1998). Underpinned loosely by a constructivist approach to pedagogy, the proposed curriculum expressed a view of children as active rather than passive learners. This view derives in large part through a recontextualised approach to the Piagetian developmental understanding of how children learn (Piaget, 1976). The new ministry of education felt that "teacher-centred instruction is inefficient and frustrating to most learners, and certainly is not consistent with education for all. Hence, we shall have to help both our teachers and learners become skilled at developing and working in learner-centred settings" (Ministry of Education and Culture, 1993: pg. 10). Therefore, the introduction of the LCE curriculum was regarded as a remedy to curb the educational inequalities of the colonial legacy while at the same time ensuring the quality and democratic educational system that would offer equity to all Namibian learners (Ministry of Education and Culture, 1993). Despite the goals of the post-colonial Namibian education system, the governments' efforts of achieving quality and accessible education to the Namibian child have not been far reaching. Many of the Namibian schools, particularly those in the rural and township areas are still far from offering the quality education as envisaged by the Namibian's educational goals due to the lack of resources and unqualified teachers (Kasanda \& Kapenda, 2015).

Moreover, the progress toward successful implementation of the LCE in Namibian schools has been challenging, despite all the efforts made to implement the new teaching approach with ease (Kapenda, 2008; Nyambe, 2015). Kapenda (2008) observed that many teachers opt for other instructional practises for knowledge transmission; hence they find it difficult to implement a "learner-centred approach". The study of Adejoke (2007) reported that most Namibian science teachers resort to traditional teaching methods in which they dominate the classroom talk with minimal or no learner participation. Further, Cantoni (2007) identified teachers' authority and their instructional practices, together with the levels of teachers' and learners' English proficiency, as major stumbling blocks to learners' being able to participate fully in their learning. Cantoni (2007) observed learners to be very passive together with examination oriented pedagogical and assessment approaches used by teachers; approaches that fail to meet 
learners' needs in terms of understanding and applying technical terms or understanding subject content. Wolfaardt (2005) found that most Namibian teachers fail to incorporate logical thinking in their lessons. According to him, teachers tend to focus mainly on facts at the expense of meaning making; that is, the mode of pedagogy is still very much rote based and teacher-centered.

Further compounding the move to learner-centred education is the fact that most of the Namibian learners in rural and township school settings, do not have adequate English competencies to cope with learning through English medium. These learners are subsequently put at an even greater disadvantage when they are suddenly switched from their mother tongue medium of instruction to an English medium in Grade 4. The move from teaching in mother tongue to teaching in English in Grade 4 is one of the key areas of interest to this paper. Against the background of curriculum reform outlined above, we wanted to investigate how a teacher navigates the difficulty entailed in teaching children in a language that is not their own, focusing specifically on how the teacher makes abstract knowledge available for acquisition. Grade 4 is that time in schooling when children move from learning to read to reading to learn. The inability to communicate in English, the medium of instruction, is sure to hamper this process. This is especially challenging in light of the implementation of the Namibian LCE that envisages learners' active participation in their own learning as well as the "promotion of learning through understanding" (Ministry of Education and Culture, 1993: p. 60). Although vast resources and attention have been given to the implementation of the revised curriculum of LCE with the hope to improve poor performance, this has not been the case, and extremely worrisome data have emerged from systemic studies with regards to poor academic performance in both primary and secondary education. The SACMEQ surveys of both 2004 and 2005 showed that Namibian learners' scores in Maths and science were very low compared to other African countries. In addition, scholars have raised concern over the current Namibian education system due to overwhelmingly poor performance in Literacy, Mathematics and Natural Science and high rates of drops out at both primary and secondary education level (Mutorwa, 2004; Makuwa, 2004; Nyambe, 2015; Wolfaardt, 2005). Wolfaardt's (2005) study reported that $22.4 \%$ of the learners were not functionally literate in English operating at the Grade 6 level, while $49.2 \%$ of grade 8 learners' numeracy skills were lower than Grade 7 level in one of the Namibian township schools. According to Wolfaardt, those learners who did not achieve the required literacy or numeracy level for Grade 8, came from schools where English was chosen, or mandated, as a medium of instruction from Grade 1. It is against this background that we seek to investigate the following questions:

1) To what extent does a teacher in a grade 4 Science classroom make concepts available to learners?

2) Does the teacher elaborate scientific concepts, that is, those concepts that must necessarily be taught and cannot be learnt spontaneously (Vygotsky, 1986)?

3) To what extent does the teacher link scientific and spontaneous concepts 
together in order to make the concepts meaningful to the learners?

While there is a body of research indicating how analogies can function (or not) to develop understanding in science classrooms, the novelty of this paper lies in the specific cultural background of second language speakers being taught science through analogies in Namibia in the context of a shifting curriculum. The cultural context of this paper, then, introduces the novelty of a group of students attempting to learn science in a language that they are not familiar with. To address the questions posed, we turn to cultural historical theory to elaborate a pedagogical model that describes learning as developmental.

\subsection{Theoretical Framework}

"The Russian word obuchenie does not admit to a direct English translation. It means both teaching and learning, both sides of the two-way process, and is therefore well suited to a dialectical view of a phenomenon made up of mutually interpenetrating opposites" (Sutton, 1980: pp. 169-170, in Reynolds \& Miller, 2003).

The above quote refers to the cultural historical view of teaching underpinned by dialectical rather than dualist logic. Here teaching and learning are dialectically entailed, two sides of one coin. Rather than the binary logic of much of Western Philosophy, Vygotsky adopted a dialectical view of development that saw the mind as both social and individual, rather than either developed socially or individually. In his book "Mind in Society" Vygotsky (1978) sets out his general genetic law that states that all higher cognitive functions, those functions that are uniquely human, begin first as actual relations between the novice and the more experienced other. Educationally, this principle is outlined in his view of the Zone of Proximal Development (ZPD). The ZPD is a unique social space opened during communicative interaction between the culturally more developed other and the novice. It is in this space that mediation, or expert guidance, happens towards the acquisition of co-constructed meaning. Through interacting with the more culturally experienced other the child begins to develop their understanding of the meanings in the world in a process of co-construction of knowledge. The development of concepts that unfolds over time in the ZPD equips the child with higher cognitive functions. The ZPD is not to be confused with scaffolding (Wood, Bruner, \& Ross, 1976) which is task or activity specific. Rather, the ZPD is a developmental zone in which meanings develop over time. This zone is very specifically the space where scientific concepts are taught.

Vygotsky (1986) distinguished between scientific and spontaneous or everyday concepts. While spontaneous concepts are learnt through interaction with the empirical world, scientific concepts must necessarily be taught as they are abstract and decontextualized. It is important to note that scientific concepts do not relate specifically to the subject of science, but rather to any concepts that need to be taught in order to be understood. Democracy, taught in history, for example, is a scientific concept. In this paper, scientific concepts are, however, related to the science knowledge taught in school. Scientific and spontaneous 
concepts, while separate, are dialectically entailed. A child cannot meaningfully engage with a scientific concept in the absence of a spontaneous concept which enables the child to make sense of the novel knowledge. Similarly, spontaneous concepts can only reach consciousness through linking to the scientific. This process happens within the ZPD, which we argue provides a space for investigating the possibility of dialogical interaction. We note that not all authors (Wegerif \& Mercer, 1997 for example) would call Vygotsky's pedagogical theory dialogical; for some, it is a very specifically monological theory. We argue, however, that the communicative interaction opened in the ZPD lends itself very specifically to dialogical pedagogy. In fact, if one considers Freire's (1998) notion of the "word" as animated only in praxis, one can see that similarities between this work and the dialectical linking of scientific and spontaneous concepts. The importance of language as the primary mediator in the development of knowledge according to Vygotsky (1986) focuses this research on the discourse that plays out in a classroom. The focus on classroom talk as playing a key role in learning is well established in the literature (Hennessy et al., 2020; Cazden, 2001; Boyd, 2015; Mercer, 2005). While Vygotsky provides a sound theoretical understanding of the linking of scientific and spontaneous concepts, his work does not provide a clear operationalisation of how this can happen in a classroom. For this, we turn to the radical-local pedagogical model outlined by Hedegaard (Hedegaard \& Chaiklin, 2005).

Hedegaard proposes that scientific and everyday concepts can be linked through a process that she terms the "double-move" in pedagogy. Drawing on the distinction Davydov (1990) makes between theoretical and empirical knowledge, Hedegaard argues that "theoretical knowledge can be conceptualised as 'symbolic tools' in the form of theories or models of subject-matter areas that can be used to understand and explain events and situations in (concrete life activities) and to organise action" (Hedegaard, 2002: p. 300). Empirical knowledge, on the other hand, is gained through the child's interaction with his or her world. In the absence of instruction, empirical knowledge can lead the child to misunderstandings (Karpov, 2005). Take for example a child who sees a shark at an aquarium. The shark has fins, swims in the sea and, for all intents and purposes is a fish; what about a dolphin though? It's entirely likely that, in the absence of knowledge about mammals, the child will assume that the dolphin is a fish. The notion of what constitutes a mammal must be taught to the child and cannot be inferred from merely looking at things that swim in water. Hedegaard proposes that the linking between abstract knowledge, scientific concepts, and everyday knowledge, spontaneous concepts, happens through a double-move in pedagogy where "...the teacher guides the learning activity both from the perspective of general concepts and from the perspective of engaging students in 'situated' problems that are meaningful in relation to their developmental stage and life situations" (Hedegaard, 1998: p. 120). This scenario requires that the teacher is familiar with the socio-cultural background of the child and can deal sensitively with what knowledge is presented to him/her by the child. It is 
through this double-move that the child begins to appropriate the meaning of abstract concepts through development. This paper looks specifically for instances of the double-move in the lessons we observed in order to understand how this can work to develop the children's understanding of photosynthesis.

\subsection{The School Context/Research Site}

The context of this study is a school located in the Northern part of Namibia about $750 \mathrm{~km}$ away from the capital city of Windhoek. The school was purposefully selected for this study from "disadvantaged" primary schools in a Namibian township in the Oshana Region. The disadvantaged schools in the Namibian context refer to Bantu (black) schools during the colonial era which were seriously underfunded and not well resourced in terms of either human or material resources which were reserved for white schools. The region where this study was conducted is regarded as one of the poorest performance regions in Maths and Science. The school is situated in a poor socio-economic environment, with surrounding informal settlements (shacks) and high rates of unemployment, crime, alcohol, and drug abuse. The school has a population of 1037 learners with 36 teachers. Most of the learners in this school come from low socio-economic circumstances. There are 4 classes per grade with approximately 38 - 40 learners in the class. Teachers and the learners in this school are both native speakers of Oshiwambo; however, they speak different dialects of Oshiwambo, which may loosely be referred to as urban Oshiwambo and rural Oshiwambo.

The school is under-resourced and has not been well maintained. There are several missing windows and the paint is peeling in various parts of the school. The school does not have a library or science labs. Most of the teachers at this school taught here before Namibian independence in 1990. English is used as medium of instruction from Grade $4-7$ while Oshiwambo is used as a medium of instruction from Grade 0 - 3. All the teachers and learners in this school are home language speakers of Oshiwambo. Learners in this school are transitioned to English medium in Grade 4. Most of the learners have limited competencies in the English language. Most of them only have access to English in the classroom. Learners from this context are believed to face the dual challenge of mastering English and at the same time learning science content through English, adding another layer of linguistic and conceptual difficulty for teaching and learning science.

The school was selected to be a subject of this study because it has been widely reported that schools situated in high poverty level areas, with children from disadvantaged backgrounds, tend to perform poorly in science subjects (see for example Fleisch, 2008). One of the objectives of the Namibian Science curriculum is to provide quality and accessible science education for students from all walks of life; this, coupled with the poor results obtained by Namibia in Science provides the basis for our focus on a science classroom. Even though the school 
charged minimal fees to compensate for additional resources that could not be supplied by the Ministry of Basic Education, many parents could not afford to pay the required amounts. Thus, this school has extremely limited resources such as texts books and science equipment; the school does not own a simple science kit to conduct simple experiments. In this school learners do not own any science textbooks and they seldom conduct science experiments.

\section{Methodology}

We adopted a case study research design to investigate the teaching of science in one classroom, over a year. We observed a Grade 4 classroom in a bilingual primary school which is located in a predominantly Oshiwambo speaking township community with few other speakers of different Namibian languages. We chose Grade 4, because it is in this grade that learners are transitioned from mother tongue medium to English medium. It is in Grade 4 that teachers are faced with the challenges of providing enough support where learners are learning Natural science content and English language simultaneously. In Namibia, like elsewhere in Africa, Grade 4 is a critical phase in which learners experience significant transitions from the lower primary phase to Junior Primary phase. It is in this grade where most of the learners are transitioned abruptly from more concrete thinking into more abstract thinking. For this study, these learners were instructed in their mother tongue medium from Grade 0 - 3; English is taught as an additional subject in grades $0-3$. As a result, these learners only had a year's exposure of five hours a week of English by the time they reached Grade 4 . These learners must deal with the challenges of learning the novel and complex language of science, while also having to learn to communicate and read in English.

In order to gather thick data (Denzin, 1989) we adopted an ethnographic approach to data collection. We videotaped lessons; took notes during lessons and collected test responses from learners. In this paper we report on the video data that were collected.

\subsection{Participants}

The participants for this study were the Natural Science teacher Mr Shilumba (pseudonyms) and his fourth-grade students. Mr Shilumba was 49 years old at the time of data collection and had a university degree in education specialising in math and science along with 16 years of teaching experience Natural Science. Mr Shilumba had taught at this school for eight years at the time of this research. He speaks four languages but is a Native speaker of Oshiwambo. Mr Shilumba was recommended to us by the head of the department as a good teacher in the Junior Primary phase who is passionate about his teaching and utilized a variety of modalities in his teaching approach to make learning more exciting for his learners. At the time of the field work, Mr Shilumba was studying part-time for an Honours degree in Education Management. In Grade $4 \mathrm{~b}$ that was the subject of this study, there were 38 emerging bilingual learners: 15 boys and 23 girls. All 
are native speakers of Oshiwambo. The lessons observed covered four units: that is plants as living organises, animals, the system of the body and communicable diseases. All the lessons were videotaped and audiotaped for data collection and analysis. In this paper we focus specifically on the lessons on photosynthesis. We report in this paper, solely on the video observations gathered.

\subsection{Data Analysis}

We undertook a qualitative analysis looking very specifically for

1) Instances of the elaboration of scientific concepts

2) Instances of everyday concepts and

3) Evidence of the linking between everyday and scientific concepts.

These broad categories are reported on in the findings in relation to the double-move in pedagogy.

\section{Findings and Discussion}

\subsection{When Analogies Fail in the Co-Construction of Knowledge}

Mr Shilumba favours an approach to teaching science that relies on the use of analogies and metaphors. Aubusson, Harrison \& Ritchie (2006) highlighted, metaphors and analogies are incorporated into science lessons to help learners to bridge their understanding and to make connections between everyday familiar concepts and the scientific concepts that are not familiar to them. With this in mind, we analysed the data for instances of analogies and metaphors used in the double-move as bridges between what is known and what is unknown. In the lesson discussion about "plants as living organisms", Mr Shilumba attempted to mediate his learners' understanding of the specialized science language by including everyday experiences, analogies and metaphors in order to construct the meaning of the targeted science concepts. The extract that follows, illustrates the occurrences where the teacher attempted to use the everyday analogies in order to lay a foundation for constructing the meaning of science concepts. The whole lesson activity is concerned with the process of photosynthesis, which is one of the most important concepts in Grade 4 Natural science under the theme: living things and non-living things. The teacher informs the class that the lesson is the continuation on the previous lesson about the plant structure and the process of photosynthesis.

\subsection{Extract 1. When an Analogy Falls Flat}

1) T: For the plant to make their own food; that process is happening where?

2) Ss: \{prolonged silent\}.

3) T: It take place in the... ( $\uparrow)$ ?

4) Ss: \{silent\}.

5) $\mathrm{T}$ : In the leaves.

6) So; those are the functions of the leaves. That's; why plants have leaves; because they cook food for the plants. We also get the oxygen through the leaves (.). We said there are tiny hole in the leaves. 
7) SS: \{learners are not paying attention; some are having private conversations; some are looking out of the window\}.

8) T: Mweneni utale! Otwati momafo omuna oumbululu; hashoo [can you please keep quiet. We said there are holes in the leaves. Is not so?].

9) Ss: ee [yes].

10) T: Do you guys understand what I'm explaining?

11) Ss: no.

12) T: Oimeno opo ininge oikulya; oya pumbwa osunlight yoenergy taidi ketango; yoo oenergy ohai pitile moumbululu vashona vomafo; ihava monika nomesho; shapo ongee tolongifa omicroscope (for the plants to make their food, they need energy from the sun, and that energy pass through the tiny holes in the leaves that we cannot see with our naked eyes. Those tiny holes (..); we cannot see them with our own eyes; but we can only see them with the microscope (using gesture of using the microscope; using hand gestures to mimic holding a microscope and moving it towards one's eyes)).

13) Ss: \{looking looked very confused from their facial expressions, some were scratching their heads, and some were biting their nails\}.

14) T: So, you see here, these are the tiny holes I'm talking about, where the gasses pass through for the plant to breath \{walking toward the chalkboard and start pointing to the drawing that was already on the chalkboard\} Do you understand?

15) SS: \{Learners looks very confused and are not paying attention; some are looking outside some are busy drawing their personal stuff\}.

16) $\mathrm{T}$ : Another function of the leaves?

17) Ss: \{prolonged silent; and most of the learners were looking outside through the window\}.

18) $\mathrm{T}$ : Is where the food is... $(\uparrow)$ ?

19) Ss: \{silent\}.

20) T: Is where the food is... $(\uparrow)$ ?

21) Ss: \{prolonged silent\}.

22) T: Is where the food is produced. So, "the plants make their own food, and they are produced in their leaves. The plants need sunlight from the sun; they need water from the soil, and they need air that is passing through their leaves" \{reading from the textbook\}.

23) S: Sir; oimeno nayo ohaiteke oikulya yayo [do plants cook their own food as well?] \{Very curious\}.

24) T: Oimeno nayo ohaiteleke oikulya yayo ndee ihai longifa oprocess yafa eihatu longifa ngee hatu teleke, for example; oimeno ihai longifa oikuni; ihai lande omakoloni; ombelela; ocooking oil; eespice, eenyanga; omatama nosho tuu komarkert [yes; plants cook their own food, but they don't use the same processes we use when we are cooking. For example, the plants don't use firewood and they do not buy macaroni, meat, cooking oil, spices, onions, tomatoes and other things from the markets]. The plants use sunlight instead of the firewood, they use mineral salt instead of salts and spices, and they also use caborn dioxide instead of oxygen. 
25) Ss: \{learners look very shocked with the mouths wide open, and they were all listening attentively\}.

26) S: Sir! Oimeno ohaili ngeipi oikulya yookaina okanya nomulungu [how do the plants eat their food, if they don't have mouth and stomach like us?].

27) T: Ondati oimeno ihaili yafa aanhu noinamwenyo, ihaili yetufa nande ohai ningi oikulya yayo [I said plants do not feel like us human beings and animals; although they make their own food].

28) Ss: \{Learners seem not satisfied with the teacher's explanation, they look very confused and some learners were scratching their heads and started talking to one another\}.

29) T: So; the moment those four ingredients are mixed up; then the plant can produce its own food through the process of photosynthesis. Photosynthesis means to cook food. Ophotosynthesis otashit; okulongekida oikulya yoshimeno $\{\mathrm{NB}$ : the exact translations\}: [photosynthesis means the preparation of the food for the plants].

In this extract, Mr Shilumba asked questions to elicit one-word answers and fill in the gap type questions, without probing to see whether learners had understood the concept (turn 1, 3, 16, 18, 20). In most of the turns, the learners did not volunteer to respond to the lower order questions, even if they were asked in both English and their mother tongue (turns 2, 4, 17, 19, 21). This is an indication that learners might not understand the science meaning presented in the previous lesson, given the fact that this part of the lesson is revising content from the previous one. After Mr Shilumba's various failed attempts to get his learners to respond to his questions, he asks the learners if they understood the process of photosynthesis (turn 10), to which they respond that they do not (turn 11). $\mathrm{Mr}$ Shilumba tries to clarify the process of photosynthesis to his learners. Firstly, he incorporates Oshiwambo as way of "bridging between the discourse" (Gibbons, 2006) (turn 12). The fact that the content he was conveying was not familiar to these learners is evidenced by the amount of confusion in their facial expressions although the content was explained in their mother tongue (turn 13). Mr. Shilumba is utilising scientific concepts (lines 6, 12, 22, 29). He quotes the meaning of photosynthesis directly from the textbook, elaborating on what the scientific concept is. However, when he moves towards linking this with the learners' everyday concepts, it is unclear that he fully grasps the essential notion of photosynthesis: that it is the process whereby plants produce food rather than, as he states, a process by which they "cook" food.

Secondly, Mr Shilumba walks to the board to show the drawing of the structure of the plant that was already drawn on the board (see Figure 1) to supplement his verbal explanation (turn 14). Mr Shilumba pointed to the leaf on the drawing, although not big enough to be seen by learners seated at the back, to show the tiny holes he was referring to. While pointing to the drawing, he explains that; "you see here, these are the tiny holes I' $m$ talking about where the gasses pass through for the plant to breathe". Learners were very confused because the tiny holes were not visible to them (turn 15). In this instance, the use 


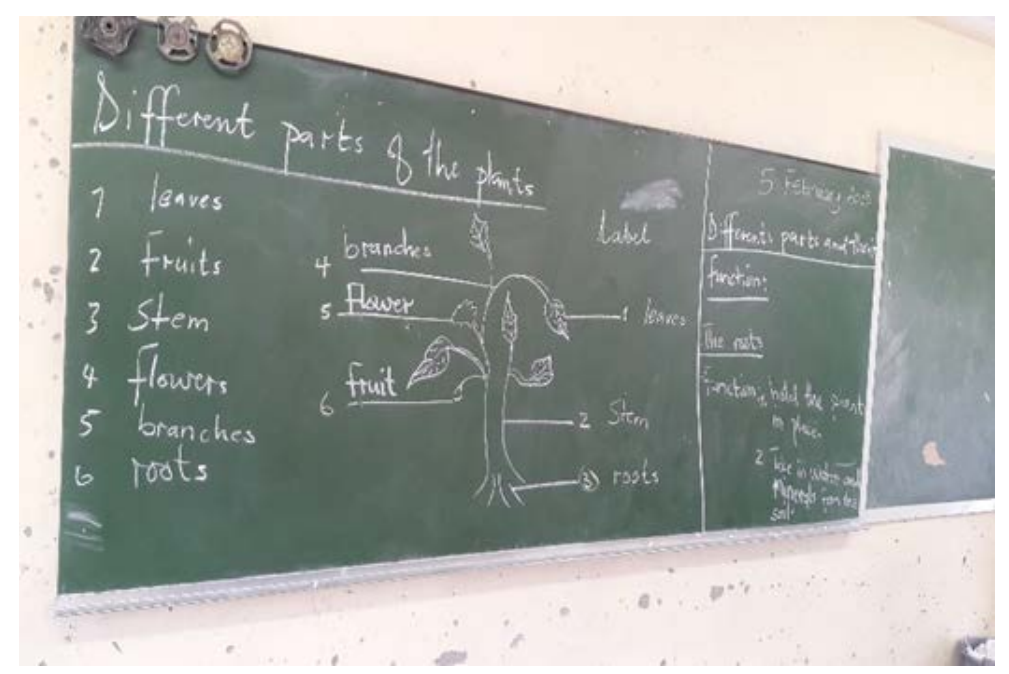

Figure 1. The drawing of the structure of the plant.

of the drawing did not help the learners to get a mental representation of the tiny holes that are found in the leaves. So again, we have the statement of the scientific concept (the purpose of leaves) but it is not linked appropriately with the concrete diagram. What we are left with then, is what Vygotsky (1986) calls mere "verbalism"- the definition of the concept without a shared meaning being generated. It is clear in moves 12, 22 and 24 that Mr Shilumba is utilising the appropriate scientific concept to describe photosynthesis in an elaborated manner. However, his explanation and use of scientific concepts here, does not lead to a shared understanding. This is because the notion of photosynthesis is what Maton (2011b) refers to as "semantically dense". There is a high cognitive demand placed on learners to grasp what cannot, essentially, be seen by the naked human eye. That is, it cannot be empirically established. This is exacerbated by the fact that learners are learning in English, a language they do not understand. In a bid to develop a shared understanding of photosynthesis, the teacher recruits an analogy (cooking), referring to an everyday concept that all learners are familiar with. However, in line 23 we can see that this analogy only confuses the learners who now think that plants cook their food, rather than understanding photosynthesis as "the process by which plants make their own food".

Mr Shilumba goes on to utilise the learners' everyday life experiences using analogies and metaphors as mediational tools to bridge more familiar knowledge and language and connect it with the targeted process of photosynthesis and its related concepts (turn 24). For instance, he tries to contextualise the process of photosynthesis by relating it to a practical and concrete experience of cooking food that learners experience in their everyday life (turn $22 \& 24$ ). While providing a recounting of a generalized account of everyday life experience of cooking in the efforts to explain the process of photosynthesis, Mr Shilumba made use of translanguaging to ensure learners' comprehension. For instance, he started explaining first in Oshiwambo; "that plants cook their own food, but they don't use the same processes as the way we cook. For example, the plants don't 
use firewood and they do not buy macaroni, meat, cooking oil, spices, onions, tomatoes and other things from the market" (turn 24). Here both languages are employed flexibly in an organised manner to mediate learners' understanding (Wei \& García, 2017).

Mr Shilumba goes on to explain in English while using the everyday life experiences analogies of using firewood to refer to the scientific idea of "sunlight energy" and the analogies of salt and spices as the metaphors of the "mineral salts" (turn 24). Here, Mr Shilumba links the scientific process of photosynthesis with the generalised event of everyday life cooking. Again, Mr Shilumba equated the ingredients for cooking with the raw materials used during the process of photosynthesis such as; sunlight energy, the carbon dioxide and water that are combined to form the final products of glucose and oxygen. This analogy fails to engage learners' social and cultural understanding, which contextualises cooking in terms of the fire they cook on. In fact, photosynthesis, an abstract notion that cannot be seen, is not like cooking food but rather relates to the notion of producing food. There is, then, a sharp contradiction between what Mr Shilumba has said and the thematic patterns he was trying to fit into (Lemke, 1990). This contradiction might cause a miscommunication of science information and confusion on the learners' behalf. There is no direct connection between the everyday life cooking experiences with the scientific process of photosynthesis. Thus, the analogy of everyday life experience of cooking does not adequately link the scientific concept of photosynthesis with the learners' everyday concepts. While an apparently perfect example of linking the scientific and everyday in the double move, this analogy fails to bridge between the learners' everyday understanding of cooking and the scientific notion of photosynthesis. This type of information might result in learners developing misconceptions and they might struggle in future to differentiate between the analogies and the realities.

As we can see in (turn 26), a learner is confused, and she asks, "how plants eat their food if they don't have mouth and stomach like human beings". Mr Shilumba responds to the learners' question in Oshiwambo, "plants do not feed like us human being, and animals, although they make their own food as well" (turn 26). Again, the teacher's use of the everyday concept of cooking, fails to link to the abstraction of photosynthesis, leaving the notion of photosynthesis a mere verbalism, that is not meaningfully appropriated by learners; Learners' facial expressions indicate that they are confused (turn 28). Mr Shilumba realises that learners need some clarification, and he tries to simplify the process of photosynthesis using a different analogy (turn 29). For instance, he says; "the moment the plants mixed up those four ingredients (referring to sunlight, mineral salts and carbon dioxide and water), they will eventually produce their own food through the process of photosynthesis". This represents a clear transmission of a misconception. Photosynthesis is not about the "mixing" up of four elements to create food; it is an everyday, rather than scientific explanation of the concept. The kind of language that Mr Shilumba produced here is what Lemke (1990) referred as; "abstract or decontextualized" language which can be misleading and 
possibly constrain effective science learning. The only occurrence where $\mathrm{Mr}$ Shilumba uses the correct everyday life metaphor is when he defines the concept of photosynthesis in (turn 29) as; "preparation of the food for the plants" to consolidate his learner's conceptual understanding. This was the only observed incident where the teacher attempted to use the metaphor that is in line with the target concept of photosynthesis in this episode. The word "preparation" is more appropriate for the process of photosynthesis than is the word "cooking". In the context of science teaching, Lemke (1990) emphasises that the thematic pattern must be appropriately fitted to the content to avoid meanings coming into conflict. Lemke (1990) warns the teacher to refrain from using generalised information that is based on here and now as well as avoiding using references that are directed to human' actions or specific events while referring to science ideas.

While analogies were supposed to serve the functions of visualising the abstract concepts and to help learners "to transfer the relationships from a familiar domain to one that is less familiar" (Mason \& Sorzio, 1996: p. 4), this is not what we see in this extract. The space for the double move in pedagogy is visible in this extract. The teacher appears to intend to link the scientific with the everyday; however, the analogy he uses has failed to realise the context in which his learners' have developed knowledge of cooking. They see cooking as a human endeavour and cannot understand why a plant, which has no mouth, could make and eat cooked food. Science meanings are not simple and easily appropriated by learners; but rather the manner in which an individual acquires and appropriates the new science discourse entails the process, as Bakhtin explains, of "populating" the new discourse with one's own intentions and purposes' (Bakhtin, 1981: p. 133). For Bakhtin (1981): “Language becomes 'one's own' when the speaker populates it with his own intention, his own accent, when he appropriates the word, adapting it to his own semantic and expressive intention" (p. 333). The way the science discourse is presented to the learners in the above extract illustrates how the use of analogies, although extremely useful tools for mediating the link between the scientific and the everyday, can fail if learners are not able to meaningfully engage with them. The process of using analogies as mediating strategies is further exacerbated by the fact that children are not being taught in their home language. Not only is the analogy failing to assist their understanding, but the very language in which the analogy is offered is not comprehended. The data reported here confirm the study of Setati et al. (2002) which refers to the incomplete journey where the mathematics teachers failed to complete a journey by moving their learners from their "informal, exploratory" talk in their home language to a more English "discourse-specific" talk and writing in a South African multilingual classroom context.

In this episode learners did not get many opportunities to practice science talking (Lemke, 1990). This is attributed to the dominant patterns of "triadic dialogue" (Lemke, 1990) which favours the teacher dominance of the dialogue while using the strategy of transmitting the knowledge to the learners that resulted in teacher-dominated monologue (Lemke, 1990). The "triadic dialogue" 
can inhibit the establishment of thematic pattern of science content while rendering the science content implicit and inaccessible to learners, regardless of the teacher's best efforts (Lemke, 1990). In the extract above, one can see how learners were confined to contributing to the discourse that was already established by the teacher's question and answer moves. While learners' talk is captured in the extract, note that it is the teacher who strongly controls the pace and sequencing of the lesson and, indeed, the construction of knowledge in this context.

We began this paper by asking three questions; whether there are scientific concepts visible in the data; whether there are everyday concepts employed in the classroom and the extent to which there is a linking between these dialectically entailed concepts in the double-move. Our analysis shows that Mr. Shilumba does indeed utilise scientific concepts. He elaborates them and points to the essence of the concept. There is also ample evidence of Mr. Shilumba attempting to utilise analogies and metaphors to link the abstract concept of photosynthesis to the learners' everyday concepts of cooking. However, in attempting to link the abstraction with the concrete, Mr. Shilumba's analogy of photosynthesis as a form of cooking, goes awry as students are unable to link the abstraction with their everyday experiences of what occurs in cooking. Analogies are extremely useful in linking abstract concepts with everyday concepts; however, as one can see from our data, this can only work where one is sensitive and cognisant of the learners' social and cultural background. In our data, the use of metaphors and analogies indicates that one must use caution when using these devices as they can lead to misconceptions. Ultimately, while Mr. Shilumba does use the double-move in pedagogy, attempting to link the abstract to the concrete, this fails for several reasons. First, we note that Mr Shilumba is operating in an environment with very few material resources. If he had a microscope, he could very well have cleared up the confusion that learners had in relation to leaves having tiny holes in them. He certainly did his best to represent this visually on the black board, but this was not enough to recruit learners' understanding. Second, the analogy of cooking food is not a particularly good analogy for what photosynthesis is, that is, the production of food. This analogy, which learners took very literally, failed to open their ZPD enabling them to co-construct the meaning of the abstract concept being taught. Third, although Mr. Shilumba is an Oshiwambo speaker, and is culturally linked to the learners through a shared language and upbringing, he has not paid enough attention to what they bring, socially and culturally, to the classroom. Hence the scientific concept is left as a mere verbalism, unpopulated with meaning.

\section{Conclusion}

This paper set out to investigate the extent to which a teacher in a rural school in Namibia utilises scientific and everyday concepts to teach science at a grade 4 level. We drew on the work of Hedegaard (1998) and Hedegaard \& Chaiklin 
(2005) to analyse the data for instances of the double-move in pedagogy where every day and scientific concepts are linked in a manner that enables the learner to meaningfully appropriate the concept. While analogies and metaphors are useful devices to link abstract concepts with every day, lived experiences, while utilising the double-move in pedagogy, our findings indicate that there are times when analogies and metaphors can lead to misconceptions rather than to theoretical knowledge. This is especially valid in a cultural context where children are not fluent in English, which is the medium of instruction. We argue that for the double-move to work with the use of analogies and metaphors, the teacher must be cognisant of recruiting learners' social and cultural context into the classroom so that meaning can be co-constructed in the ZPD.

\section{Conflicts of Interest}

The authors declare no conflicts of interest regarding the publication of this paper.

\section{References}

Adejoke, A. G. (2007). An Investigation into Knowledge and Practices of Learner-Centred Methods of Teaching by Physical Science Teachers in the Omusati Education Region. Unpublished Master's Thesis. Windhoek: University of Namibia.

Aubusson, P. J., Harrison, A. G., \& Ritchie, S. M. (2006). Metaphor and Analogy in Science Education. Dordrecht: Springer Press.

https://doi.org/10.1007/1-4020-3830-5

Bakhtin, M. M. (1981). Discourse in the Novel. In M. Holquist (Ed.), The Dialogic Imagination: Four Essays. Austin, TX: University of Texas Press.

Boyd, M. P. (2015). Relations between Teacher Questioning and Student Talk in One Elementary ELL Classroom. Journal of Literacy Research, 47, 370-404. https://doi.org/10.1177\%2F1086296X16632451

Cantoni, M. (2007). What Role Does the Language of Instruction Play for a Successful Education? A Case Study of the Impact of Language Choice in a Namibian School. Vaxjo: Växjö University Press.

Cazden, C. B. (2001). Classroom Discourse: The Language of Teaching and Learning (2nd ed.). Portsmouth, NH: Heinemann.

Davydov, V. (1990). Soviet Studies in Mathematics Education: Volume 2. Types of Generalizations in Instruction: Logical and Psychological Problem in the Structuring of School Curricula. Reston: The National Council of Teachers of Mathematics.

Denzin, N. (1989). Interpretive Biography. California, CA: Sage. https://dx.doi.org/10.4135/9781412984584

Fleisch, B. (2008). Primary Education in Crisis. Why South African School Children under Achieve in Reading and Mathematics. Cape Town: Juta.

Freire, P. (1998). Pedagogy of Freedom. Ethics, Democracy and Civiccourage. New York, NY: Rowman \& Littlefield Publishers.

Gibbons, P. (2006). Bridging Discourses in the ESL Classroom: Students, Teachers, and Researchers. London: Continuum.

Hedegaard, M. (1998). Situated Learning and Cognition: Theoretical Learning and Cog- 
nition. Mind, Culture and Activity, 5, 114-126.

https://doi.org/10.1207/s15327884mca0502 5

Hedegaard, M. (2002). Learning and Child Development: A Cultural-Historical Study. Aarhus: Aarhus University Press.

Hedegaard, M. (2009). Children's Development from a Cultural-Historical Approach: Children's Activity in Everyday Local Settings as Foundation for Their Development. Mind, Culture and Activity, 16, 64-81. https://doi.org/10.1080/10749030802477374

Hedegaard, M., \& Chaiklin, S. (2005). Radical-Local Teaching and Learning. Aarhus: University of Aarhus Press.

Hennessy, S., Howe, C., Mercer, N., \& Vrikki, M. (2020). Coding Classroom Dialogue: Methodological Considerations for Researchers. Learning, Culture and Social Interaction, 25, Article ID: 100404. https://doi.org/10.1016/j.lcsi.2020.100404

Kapenda, H. M. (2008). Translating Policy into Practice: Aspects of Learner-Centred Classroom Practice in Mathematics in Namibia Secondary Schools. Unpublished PhD Thesis. Cape Town: University of Western Cape.

Karpov, V. Y. (2005). The Neo-Vygotskian Approach to Child Development. Cambridge: Cambridge University Press. https://doi.org/10.1017/CBO9781316036532

Kasanda, C. D., \& Kapenda, H. M. (2015). School Learners' Knowledge and Views of Traditional Medicinal Plant Use in Two Regions in Namibia. In K. C. Chinsembu, A. Cheikhyoussef, D. R. Mumbengegwi, M. Kandawa-Schulz, C. D. Kasandra, \& L. Kazembe (Eds.), Indigenous Knowledge of Namibia. Windhoek: University of Namibia Press, 135-156. https://doi.org/10.2307/j.ctvgc619h

Lemke, J. (1990). Talking Science: Language, Learning and Values. Norwood, NJ: Ablex Publishing Corporation.

Makuwa, D. K. (2004). The SACMEQ 11 Report: A Study of the Conditions of Schooling and the Quality of Primary Education in Namibia. Windhoek: Directorate of Planning and Development.

Mason, L., \& Sorzio, P. (1996). Analogical Reasoning in Restructuring Scientific Knowledge. European Journal of Psychological of Education, 11, 3-23.

https://doi.org/10.1007/BF03172933

Maton, K. (2011b). Theories and Things: The Semantics of disciplinarity. In F. Christie, \& K. Maton (Eds.), Disciplinarity: Functional Linguistic and Sociological Perspectives (pp. 62-84). London: Continuum.

Mercer, N. (2005). Sociocultural Discourse Analysis: Analysing Classroom Talk as a Social Mode of Thinking. Journal of Applied Linguistics, 1, 137-168.

https://dx.doi.org/10.1558/japl.v1i2.137

Ministry of Education and Culture (1993). Education for All. Windhoek: Gamsberg MacMillan

Ministry of Education and Culture (2003). Learner-Centred Education in the Namibian Context. Discussion Document. Okahandja: National Institute for Educational Development.

Ministry of Education and Culture (2008). National Policy Guide for Social Studies. Okahandja: National Institute for Educational Development.

Mutorwa, J. (2004). National Report on the Development of Education in Namibia. International Conference on Education: Geneva 2004, Geneva, 8-11 September 2004, 16-21.

Nyambe, T. N. (2015). Primary Teachers' Experiences of Implementing Assessment Policy in Social Studies in the Okavango Region of Namibia. Unpublished Master's Thesis, 
Stellenbosch: Stellenbosch University.

Piaget, J. (1976) Piaget's Theory. In B. Inhelder, H. H. Chipman, \& C. Zwingmann (Eds.), Piaget and His School (pp. 11-23). Berlin, Heidelberg: Springer.

https://doi.org/10.1007/978-3-642-46323-5 2

Reynolds, W., \& Miller, E. (2003). The Handbook of Psychology (7th ed.). Hoboken, NJ: John Wiley and Sons.

Setati, M., Adler, J., Reed, Y., \& Bapoo, A. (2002). Incomplete Journeys: Code-Switching and Other Language Practices in Mathematics, Science and English Language Classrooms in South Africa. Language and Education, 16, 128-149.

https://doi.org/10.1080/09500780208666824

Sutton, A. (1980). Backward Children in the USSR. In J. Brine, A. Perry, \& S. Andrew (Eds.), Home, School, and Leisure in the Soviet Union (pp. 34-42). St. Lenards: Allen \& Unwin.

Tabachnick, B. R. (1998) Useful Educational Research in a Transforming Society. Journal of Education for Teaching, 24, 101-108. https://doi.org/10.1080/02607479819818

Vygotsky, L. S. (1978). Mind in Society. Cambridge, MA: Harvard University Press.

Vygotsky, L. S. (1981). The Genesis of Higher Mental Functions. In J. V. Wertsch (Ed.) The Concept of Activity in Soviet Psychology (pp. 144-188). Armonk, NY: M.E. Sharpe.

Vygotsky, L. S. (1986). Thought and Language. Cambridge, MA: MIT Press.

Wegerif, R., \& Mercer, N. (1997). Using Computer-Based Analysis to Integrate Quantitative and Qualitative Methods in the Investigation of Collaborative Learning. Language and Education, 11, 271-286. https://doi.org/10.1080/09500789708666733

Wei, L., \& García, O. (2017). From Researching Translanguaging to Translanguaging Research. In K. Kendall, Y. J. Lai, \& S. May (Eds.), Research Methods. Encyclopedia of Language and Education (pp. 227-240.). Cham: Springer.

https://doi.org/10.1007/978-3-319-02249-9 16

Wolfaardt, D. (2005). Namibia: A Case for a Gradual Transitional Bilingual Language Programme. In J. Cohen, K. T. McAlister, K. Rolstad, \& J. MacSwan (Eds.), Proceedings of the 4th International Symposium on Bilingualism (pp. 2357-2368). Somerville, MA: Cascadilla Press. http://www.lingerf.com/isb/4/184ISB4.PDF

Wood, D., Bruner, J. S., \& Ross, G. (1976). The Role of Tutoring in Problem Solving. Journal of Child Psychology and Psychiatry, 17, 89-100.

https://doi.org/10.1111/j.1469-7610.1976.tb00381.x 